\title{
Efeitos das restrições pré e pós-natal sobre o crescimento e desempenho de cordeiros Santa Inês do desmame ao abate ${ }^{1}$
}

\author{
Luciana Castro Geraseev², Juan Ramón O. Perez ${ }^{3}$, Paulo Afonso Carvalho ${ }^{4}$, Bruno Carneiro Pedreira ${ }^{5}$, \\ Thaís Romano V. Almeida 4
}

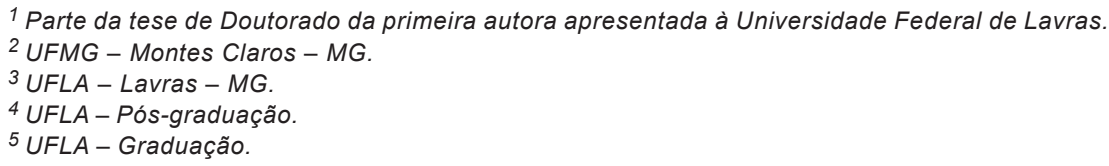

RESUMO - Objetivou-se com este estudo avaliar os efeitos das restrições pré e pós-natal sobre o crescimento e desempenho de cordeiros Santa Inês do desmame ao abate. Foram utilizados 48 cordeiros machos, divididos em três grupos: restrição pré-natal (RPRE), restrição pós-natal (RPOS) e nenhum tipo de restrição (controle). Após o desmame, o consumo médio de ração dos cordeiros da RPOS foi inferior aos dos demais, em razão do controle no fornecimento do alimento, sendo que as médias para os grupo controle, RPRE e RPOS foram, respectivamente, de 757,765 e $624 \mathrm{~g} / \mathrm{dia}$. Os animais do grupo controle apresentaram os menores consumos totais de ração, em decorrência da menor idade de abate, em comparação aos cordeiros com alimentação restrita, acarretando menor tempo de confinamento. A análise da curva de crescimento comprovou que o ganho médio dos cordeiros do grupo controle (257 g/dia) foi superior ao dos cordeiros RPOS (155g/dia) e RPRE (198 g/dia). O desempenho inferior dos cordeiros com alimentação restrita em relação aos do grupo controle após o desmame indica que os animais não compensaram a restrição imposta e, portanto, apresentaram valores mais altos para idade de abate, consumo total de ração e tempo de ocupação da instalação.

Palavras-chave: nutrição pós-natal, nutrição pré-natal, ovinos, restrição alimentar

\section{Effects of pre and postnatal feed restriction on growth and production of Santa Inês lambs from weaning to slaughter}

\begin{abstract}
This experiment was conducted to evaluate the effects of pre and postnatal feed restriction on growth and production of Santa Inês lambs from weaning to slaughter. Forty-eight lambs were assigned to three treatments as follows: lambs with prenatal feed restriction (PRER), lambs with postnatal feed restriction (POSTR), and lambs with no feed restriction (Control). Average daily feed intake (as fed basis) of lambs on POSTR treatment $(624 \mathrm{~g} / \mathrm{d})$ was significantly lower $(P<0.05)$ than that of lambs on control $(757 \mathrm{~g} / \mathrm{d})$ and PRER $(765 \mathrm{~g} / \mathrm{d})$ treatments possibly because of the feed restriction after birth. However, total feed intake was lowest on control, which may be explained by the earlier slaughter age of lambs in this treatment compared to feed-restricted animals. Daily weight gain of non-restricted lambs (Control) averaged $257 \mathrm{~g} / \mathrm{d}$ and was greater than the daily weight gain of POSR and PRER treatments that averaged 155 and $198 \mathrm{~g} / \mathrm{d}$, respectively. Lower after weaning production on PRER and POSR treatments compared to control indicated that feed-restricted animals were not able to compensate the imposed restriction leading to later slaughter age and higher feed consumption.
\end{abstract}

Key Words: feed restriction, postnatal nutrition, prenatal nutrition, sheep

\section{Introdução}

Segundo Lanna (1997), quando se trabalha com a produção de animais destinados ao abate, deve-se buscar a otimização do crescimento pré e pós-natal. Portanto, a pesquisa nesta área deve descrever as curvas de crescimento animal nessas fases e estudar os efeitos dos diferentes fatores que a influenciam, sobretudo a nutrição, o manejo e a genética.

Pela nutrição é possível alterar a curva de crescimento e a composição corporal dos animais, de modo que os efeitos variem conforme o grau e o tempo de manipulação. Várias pesquisas indicam que as fases mais críticas à alteração na composição corporal por meio da nutrição são o período pré-natal e o início do crescimento do animal, pois nesta fase a disponibilidade de nutrientes determina o grau de expressão do potencial genético do animal.

Durante o crescimento fetal, particularmente nos estágios críticos de diferenciação, a baixa disponibilidade de nutrientes, decorrente de nutrição inadequada da fêmea, pode comprometer o desenvolvimento de alguns órgãos, afetando a fisiologia do animal após o nascimento.

Correspondências devem ser enviadas para: Igeraseev@nca.ufmg.br 
Greenwood et al. (1998) afirmam que a restrição no período pré-natal afeta o metabolismo energético do animal, principalmente nas primeiras semanas de vida. De acordo com esses autores, animais submetidos à restrição alimentar pré-natal possuem capacidade limitada de utilização da energia para deposição de tecidos, o que resulta em menor crescimento.

Assim, o nível nutricional afeta a fisiologia do animal, alterando sua curva de crescimento pré e pós-natal, modificando a idade e o peso em que ocorre a aceleração ou desaceleração do crescimento de cada tecido, com conseqüente alteração na composição corporal desses animais.

A importância da realização de pesquisas nesta área está relacionada à estreita relação entre o nível nutricional e o retorno econômico da produção de cordeiros, pois, além do grande impacto sobre a variável-resposta desta atividade (o crescimento), a alimentação é um dos fatores que mais oneram o custo de produção.

Este trabalho foi conduzido com o objetivo de avaliar os efeitos das restrições pré e pós-natal sobre o crescimento e o desempenho de cordeiros da raça Santa Inês após o desmame.

\section{Material e Métodos}

O experimento foi conduzido no Setor de Ovinocultura do Departamento de Zootecnia da Universidade Federal de Lavras (UFLA) no período de março de 2000 a novembro de 2001. Foram utilizados 48 cordeiros da raça Santa Inês, dos quais 24 eram filhos de ovelhas que sofreram restrição energética durante o terço final da gestação e os demais, filhos de ovelhas que não sofreram restrição alimentar durante a gestação. Os cordeiros nascidos de fêmeas que não sofreram restrição durante a gestação foram divididos em dois grupos (um recebeu alimentação à vontade e o outro, alimentação restrita do nascimento ao abate) para que pudessem ser identificados os efeitos tanto da restrição pré quanto pós-natal.
Tabela 1 - Esquema experimental

Table 1 - Experimental design

Peso ao abate

Tratamento

Slaughter weigth Treatment

Restrição pré-natal Restrição Pós-Natal Controle Prenatal restriction Postnatal restriction Control

\begin{tabular}{llll}
\hline $15 \mathrm{~kg}$ & 4 & 4 & 4 \\
$25 \mathrm{~kg}$ & 4 & 4 & 4 \\
$35 \mathrm{~kg}$ & 4 & 4 & 4 \\
$45 \mathrm{~kg}$ & 4 & 4 & 4 \\
\hline
\end{tabular}

Assim, os tratamentos foram compostos por três grupos de cordeiros: um grupo que sofreu restrição pré-natal, um que sofreu restrição pós-natal e outro que não sofreu nenhuma das restrições (cordeiros controle). Em cada grupo, os animais foram abatidos com diversos pesos, conforme descrito na Tabela 1.

Os cordeiros permaneceram com suas mães durante três dias após o nascimento para mamar o colostro. Em seguida, foram separados e alojados em baias coletivas até os 15 dias de idade, quando foram alojados individualmente. Após a separação das mães, os cordeiros foram aleitados artificialmente até os 60 dias de idade.

Durante todo o período experimental, os animais foram alimentados duas vezes ao dia, às 7 e 16h, com uma dieta experimental (Tabelas 2 e 3 ) balanceada para atender às exigências em proteína, energia metabolizável e minerais, para mantença e crescimento, segundo recomendações do ARC(1980).

Aos animais dos grupos controle e restrição pré-natal foram fornecidas quantidades de ração suficientes para haver sobras de $30 \%$ do total oferecido e, aos do grupo alimentação restrita pós-natal, quantidades de ração para permitir ganho de peso diário de $150 \mathrm{~g}$.

Diariamente, efetuou-se controle do consumo, pela pesagem e amostragem da ração fornecida e das sobras. Posteriormente, a cada 14 dias, formaram-se amostras compostas

Tabela 2 - Composição químico-bromatológica dos ingredientes da dieta, \% MS

Table 2 - Chemical composition of diet ingredients, DM basis

\begin{tabular}{|c|c|c|c|c|c|c|}
\hline $\begin{array}{l}\text { Ingrediente } \\
\text { Ingredient }\end{array}$ & $\begin{array}{c}\mathrm{MS}(\%) \\
D M\end{array}$ & $\begin{array}{c}\text { PB }(\%) \\
C P\end{array}$ & $\begin{array}{c}\text { FDN }(\%) \\
N D F\end{array}$ & $\begin{array}{c}\text { FDA }(\%) \\
A D F\end{array}$ & $\mathrm{Ca}(\%)$ & $\mathrm{P}(\%)$ \\
\hline Feno de coastcross (Coast cross hay) & 91,30 & 8,53 & 78,63 & 33,93 & 0,733 & 0,434 \\
\hline Milho grão (Corn) & 86,77 & 10,56 & 21,58 & 4,03 & 0,063 & 0,311 \\
\hline Farelo de soja (Soybean meal) & 88,40 & 45,62 & 20,70 & 10,17 & 0,452 & 0,781 \\
\hline Calcário calcítico (Limestone) & 99,99 & - & - & - & 35,84 & - \\
\hline Sal comum (Salt) & 99,82 & - & - & - & - & - \\
\hline Suplemento Min./Vit. ${ }^{1}$ (Mineral/vitamin supplement) & 94,36 & - & - & - & 23,00 & 9,00 \\
\hline
\end{tabular}

${ }^{1}$ Nutrientes $/ \mathrm{kg}$ de suplemento (Nutrients per $\mathrm{kg}$ of supplement): $\mathrm{Ca}=230 \mathrm{~g}: P=90 \mathrm{~g}: \mathrm{S}=15 \mathrm{~g} ; \mathrm{Mg}=20 \mathrm{~g} ; \mathrm{Na}=48 \mathrm{~g} ; \mathrm{Co}=100 \mathrm{mg}: \mathrm{Cu}=700 \mathrm{mg} ; \mathrm{Fe}=2.000 \mathrm{mg}$ $I=80 \mathrm{mg} ; \mathrm{Mn}=1250 \mathrm{mg} ; \mathrm{Se}=200 \mathrm{mg} ; \mathrm{Zn}=2.700 \mathrm{mg} ; \mathrm{F}=900 \mathrm{mg} ; \mathrm{Vit}$. $A=200.000 \mathrm{UI}$, Vit.D3 = 60.000 UI; Vit $E=60 \mathrm{UI}$. 
Tabela 3 - Composição químico-bromatológica e participação centesimal (\% MS) dos ingredientes da dieta experimental Table 3 - Chemical and ingredient composition of the experimental diet

\begin{tabular}{|c|c|c|c|c|c|c|c|}
\hline $\begin{array}{l}\text { Ingrediente } \\
\text { Ingredient }\end{array}$ & $\begin{array}{c}\mathrm{MS}(\%) \\
D M\end{array}$ & $\begin{array}{c}\mathrm{EM}^{1}(\mathrm{kcal} / \mathrm{kg}) \\
E M\end{array}$ & $\begin{array}{c}\mathrm{PB}(\%) \\
C P\end{array}$ & $\begin{array}{l}\text { FDN (\%) } \\
\quad N D F\end{array}$ & $\begin{array}{c}\text { FDA }(\%) \\
A D F\end{array}$ & $\mathrm{Ca}(\%)$ & $\mathrm{P}(\%)$ \\
\hline Feno de coastcross (Coastcross hay) & 20,88 & 1,78 & 16,42 & 7,08 & 0,153 & 0,091 & \\
\hline Milho grão (Corn) & 59,26 & 6,26 & 12,78 & 2,39 & 0,037 & 0,184 & \\
\hline Calcário calcítico (Limestone) & 0,90 & - & - & - & 0,322 & - & \\
\hline Sal comum (Sodium chloride) & 0,28 & - & - & - & - & - & \\
\hline Sup.Min./Vit. (Mineral/vitamin supplement) & 1,97 & - & - & - & 0,453 & 0,177 & \\
\hline
\end{tabular}

1 Valor obtido no ensaio de digestibilidade.

1 Value obtained in a digestibility trial.

por animal, que foram acondicionadas e armazenadas para análises laboratoriais.

O controle do desenvolvimento dos animais foi feito por meio de pesagens semanais, realizadas sempre pela manhã, antes do fornecimento da ração, visando à obtenção das taxas de crescimento e de ganho de peso médio diário.

As análises químicas foram efetuadas no Laboratório de Nutrição Animal do Departamento de Zootecnia da Universidade Federal de Lavras, segundo metodologia descrita por Silva \& Queiroz (2002). Nas amostras dos ingredientes da dieta e das sobras, foram determinados os teores de MS, FDN, FDA, PB, cinzas, Ca e P.

O período experimental não teve duração pré-fixada, pois correspondeu ao período necessário para que os animais atingissem o peso pré-determinado para o abate.

O desempenho dos animais foi avaliado considerando-se os consumos médio e total de ração, os consumos de $\mathrm{MS} / \mathrm{kg} \mathrm{PV}{ }^{0,75}$, de EM/kg PV ${ }^{0,75}$, de PB/kg PV ${ }^{0,75}$ e de FDN/kg $\mathrm{PV}^{0,75}$, a idade ao abate, o ganho de peso médio diário e a conversão alimentar dos cordeiros em cada tratamento.

Para a análise desses dados, adotou-se delineamento experimental inteiramente casualizado em esquema fatorial $3 \times 4$ (três tratamentos: grupo controle, restrição pré-natal e restrição pós-natal e quatro pesos de abate: $15,25,35$ e 45 $\mathrm{kg}$ ), com quatro repetições, em que cada animal representou uma unidade experimental. Essas variáveis foram analisadas utilizando-se o seguinte modelo estatístico:

$$
\mathrm{Y}_{\mathrm{ijk}}=\mu+\alpha_{\mathrm{i}}+\beta_{\mathrm{j}}+(\alpha \beta)_{\mathrm{ij}}+\varepsilon_{(\mathrm{ij}) \mathrm{k}}
$$

em que $Y_{\mathrm{ijk}}$ são os valores observados para as variáveis supracitadas no nível i de tratamentos de restrição e no nível $\mathrm{j}$ de peso de abate, na repetição $\mathrm{k}(\mathrm{k}=1,2,3,4)$; $\mu$, a média geral; $\alpha_{i}$, o efeito do nível i de tratamentos $(i=1,2,3) ; \beta_{j}$, o efeito do nível j de pesos de abate $(\mathrm{j}=1,2,3,4) ;(\alpha \beta)_{\mathrm{ij}}$, o efeito da interação dos fatores tratamentos e pesos de abate; e $\varepsilon_{(\mathrm{ij}) \mathrm{k}}$, o erro experimental associado à observação $Y_{\mathrm{ijk}}$, que, por hipótese, tem distribuição normal com média zero e variância $\sigma^{2}$.
A curva de crescimento dos animais foi obtida utilizando-se a idade e os pesos ao desmame e ao abate dos animais. A análise de crescimento dos animais foi realizada por meio de equações de regressão do peso em função da idade dos animais. O modelo estatístico utilizado neste caso foi:

$$
\mathrm{Y}_{\mathrm{ij}}=\mu+\mathrm{b}_{1} \mathrm{x}_{1 \mathrm{i}}+\mathrm{e}_{\mathrm{ij}}
$$

em que $Y_{i j}$ são os valores observados para o peso do animal $(\mathrm{kg})$ no nível i de tratamentos de restrição, na repetição j; $\mu$, a média geral; $\mathrm{b}_{1}$, o coeficiente de regressão; $\mathrm{x}_{1 \mathrm{i}}$, idade do animal; $e_{i j}$, o erro experimental associado à observação Yij, que, por hipótese, tem distribuição normal com média zero e variância $\sigma^{2}$.

\section{Resultados e Discussão}

$\mathrm{Na}$ Tabela 4 encontram-se os valores referentes ao consumo médio diário total da dieta (g/dia) do desmame ao abate dos cordeiros dos grupos controle, restrição prénatal e restrição pós-natal.

Observou-se que, independentemente do manejo alimentar, houve aumento no consumo médio diário de ração de acordo com o aumento no peso vivo dos cordeiros. Além disso, os animais de $15 \mathrm{~kg}$ apresentaram consumo significativamente menor que aqueles com outros pesos, em razão de sua menor capacidade de ingestão e do estresse causado pela desmama, que ocorreu próximo a este peso.

A média geral do consumo diário de ração foi semelhante para os cordeiros dos grupos controle e restrição pré-natal. As médias gerais de consumo obtidas neste estudo para animais sem restrição pós-natal (742 e $765 \mathrm{~g} / \mathrm{dia})$ foram inferiores às encontradas por Santos (2002), ao avaliarem cordeiros Santa Inês puros. Foram superiores, no entanto, aos valores descritos por Kirkpatrick \& Steen (1999) e Pires et al. (2000), que encontraram consumo médio de $712 \mathrm{~g} / \mathrm{dia}$ para cordeiros Texel x Ideal e de 521g/dia para cordeiros Ductch Texel x Greyface. 
Tabela 4 - Consumo médio diário total (g/dia) da dieta do desmame ao abate dos cordeiros dos grupos controle, restrição alimentar pós-natal e com restrição alimentar prénatal, com base na matéria natural

Table 4 - Average feed intake (g/day), as-fed basis, of control, postnatal and prenatal restricted lambs from weaning to slaughter

\begin{tabular}{lccc}
\hline $\begin{array}{l}\text { Peso ao abate } \\
\text { Slaughter weight }\end{array}$ & \multicolumn{3}{c}{$\begin{array}{c}\text { Tratamento } \\
\text { Treatment }\end{array}$} \\
\cline { 2 - 4 } & $\begin{array}{c}\text { Restrição pré-natal } \\
\text { Prenatal restriction }\end{array}$ & $\begin{array}{c}\text { Restrição pós-natal } \\
\text { Postnatal restriction }\end{array}$ & $\begin{array}{c}\text { Controle } \\
\text { Control }\end{array}$ \\
\hline 45 & $1052^{\mathrm{aA}}$ & $771^{\mathrm{bA}}$ & $1002^{\mathrm{aA}}$ \\
35 & $860^{\mathrm{aB}}$ & $655^{\mathrm{bB}}$ & $890^{\mathrm{aB}}$ \\
25 & $749^{\mathrm{aB}}$ & $595^{\mathrm{bC}}$ & $752^{\mathrm{aB}}$ \\
15 & $367^{\mathrm{aC}}$ & $477^{\mathrm{aD}}$ & $418^{\mathrm{aC}}$ \\
Média geral $^{1}$ & $757^{\mathrm{a}}$ & $624^{\mathrm{b}}$ & $765^{\mathrm{a}}$ \\
Overall mean $^{\text {Pvear }}$ & & & \\
\hline
\end{tabular}

Médias seguidas da mesma letra minúscula na linha e maiúscula na coluna não diferem $(P<0,05)$ pelo teste Scott-Knott.

Means within a row followed by the same small letters and same capital letters do not differ $(P<0.05)$ by Scott-Knott test.

${ }^{1}$ Coeficiente de variação $(\%)=11,17$

${ }^{1}$ Coefficient of variation $(\%)=11.17$

Os cordeiros do grupo restrição pós-natal apresentaram consumo médio geral inferior ao dos demais, como resultado do controle no forneciemento do alimento. A eficiência do controle imposto aos animais sob restrição pós-natal pode ser comprovada pelo menor consumo de matéria seca, proteína e FDN por quilo de peso metabólico (Tabela 8) apresentado por estes animais.

Na Tabela 5 são apresentados os valores referentes ao consumo total de ração $(\mathrm{kg})$ pelos cordeiros do desmame ao abate. Embora os animais submetidos à restrição pós-natal tenham apresentado menor média de consumo diário (Tabela4), quando se considerou o consumo total de ração, constatou-se que essa variável foi menor para os cordeiros do grupo controle, provavelmente em razão da menor idade ao abate (menor tempo de confinamento) destes animais em relação àqueles com restrições pré e pós-natal (Tabela 6).

A média da idade ao abate para cordeiros sem restrição pós-natal variou de 78 a 165 dias (controle) e de 118 a 209 dias (restrição pré-natal) e foi inferior às encontradas por Furusho-Garcia et al. (2004), de 107 e 254 dias, em animais machos inteiros da raça Santa Inês abatidos com 15 e $45 \mathrm{~kg}$ de PV, respectivamente.

Quanto aos efeitos da restrição sobre a idade de abate, verificou-se que a média geral dos cordeiros controle foi inferior à dos animais sob restrição, como reflexo do maior ganho de peso desses animais após o desmame (Tabela 7). Entre os animais com alimentação restrita, aqueles da restrição pré-natal apresentaram ganho de peso superior (Tabela 7) aos da restrição pós-natal e, conseqüentemente, menor idade de abate, evidenciando que, nesta fase, desde que o
Tabela 5 - Consumo total de ração $(\mathrm{kg})$, com base na matéria natural, do desmame ao abate dos cordeiros dos grupos controle, com restrição alimentar pós-natal e com restrição alimentar pré-natal

Table 5 - Total feed intake $(\mathrm{kg})$, as-fed basis, of control, postnata and prenatal restricted lambs from weaning to slaughter

\begin{tabular}{lccc}
\hline $\begin{array}{c}\text { Peso ao abate } \\
\text { Slaughter weight }\end{array}$ & \multicolumn{3}{c}{$\begin{array}{c}\text { Tratamento } \\
\text { Treatment }\end{array}$} \\
\cline { 2 - 4 } & $\begin{array}{c}\text { Restrição pré-natal } \\
\text { Prenatal restriction }\end{array}$ & $\begin{array}{c}\text { Restrição pós-natal Controle } \\
\text { Postnatal restriction }\end{array}$ & Control \\
\hline 45 & $108,3^{\mathrm{aA}}$ & $147,9^{\mathrm{bA}}$ & $148,0^{\mathrm{bA}}$ \\
35 & $64,2^{\mathrm{aB}}$ & $90,2^{\mathrm{bB}}$ & $100,9^{\mathrm{bB}}$ \\
25 & $33,9^{\mathrm{aC}}$ & $49,9^{\mathrm{aC}}$ & $57,3^{\mathrm{aC}}$ \\
15 & $7,1^{\mathrm{aD}}$ & $14,5^{\mathrm{aD}}$ & $23,4^{\mathrm{aD}}$ \\
${\text { Média } \text { geral }^{1}}^{53,39^{\mathrm{b}}}$ & $75,63^{\mathrm{a}}$ & $82,41^{\mathrm{a}}$
\end{tabular}

Overall mean

Médias seguidas da mesma letra minúscula na linha e maiúscula na coluna não diferem $(P<0,05)$ pelo teste Scott-Knott.

Means within a row followed by the same small letters and same capital letters do not differ $(P<0.05)$ by Scott-Knott test.

1 Coeficiente de variação $(\%)=15,70$.

${ }^{1}$ Coefficient of variation $(\%)=15.70$.

animal seja submetido a um manejo nutricional adequado, os efeitos deste tipo de restrição são menores que os impostos pela restrição pós-natal.

A diferença no ganho de peso dos cordeiros submetidos à restrição pré-natal em relação aos do grupo controle pode ser explicada pela alteração no peso à maturidade destes animais. Segundo Wynn \& Thwaites (1981), o peso à maturidade pode ser definido como o peso no qual o animal atinge a máxima deposição de matéria desengordurada.

De acordo com Lanna (1997), a precocidade ou taxa com que o animal se aproxima do seu peso à idade adulta e ao abate é muito sensível às alterações do ambiente e, especialmente, ao nível nutricional. Deste modo, restrições alimentares severas no período pré e perinatal podem comprometer o peso adulto do animal, alterando o peso em que atinge máxima deposição de matéria desengordurada e de gordura. As conseqüências são a diminuição da eficiência do ganho de peso, uma vez que a deposição de peso na forma de músculo é aproximadamente quatro vezes mais eficiente que a de tecido adiposo (Greenwood et al., 1998).

Esses dados evidenciam os danos das restrições pré e pós-natal no desenvolvimento do animal e o impacto nos dias de confinamento necessários para que esses animais atinjam o peso ideal de abate. Essa informação é de suma importância, pois afeta diretamente a viabilidade econômica da criação de cordeiros para corte.

Entretanto, ressalta-se que os efeitos da restrição prénatal ainda causam reflexos no desempenho do animal mesmo quando submetido a um manejo nutricional correto 
Tabela 6 - Idade ao abate (dias) dos cordeiros dos grupos controle, restrição alimentar pós-natal e restrição alimentar pré-natal, abatidos com diferentes pesos

Table 6 - Slaughter age (days) of control, postnatal and prenatal restricted lambs after weaning

\begin{tabular}{lccc}
\hline $\begin{array}{l}\text { Peso ao abate } \\
\text { Slaughter weight }\end{array}$ & \multicolumn{3}{c}{$\begin{array}{c}\text { Tratamento } \\
\text { Treatment }\end{array}$} \\
\cline { 2 - 4 } & $\begin{array}{c}\text { Restrição pré-natal } \\
\text { Prenatal restriction }\end{array}$ & $\begin{array}{c}\text { Restrição pós-natal Controle } \\
\text { Postnatal restriction }\end{array}$ & Control \\
\hline 45 & $165^{\mathrm{aC}}$ & $254^{\mathrm{cD}}$ & $209^{\mathrm{bB}}$ \\
35 & $135^{\mathrm{aB}}$ & $200^{\mathrm{cC}}$ & $176^{\mathrm{bB}}$ \\
25 & $118^{\mathrm{aB}}$ & $155^{\mathrm{aB}}$ & $140^{\mathrm{aA}}$ \\
15 & $78^{\mathrm{aA}}$ & $89^{\mathrm{aA}}$ & $118^{\mathrm{bA}}$ \\
Média geral & $124^{\mathrm{a}}$ & $174^{\mathrm{c}}$ & $161^{\mathrm{b}}$ \\
Overall mean & & & \\
\hline
\end{tabular}

Médias seguidas da mesma letra minúscula na linha e maiúscula na coluna não diferem pelo teste Scott-Knott $(P<0,05)$.

Means within a row followed by the same small letters and same capital letters do not differ by Scott-Knott test $(P<0.05)$.

${ }^{1}$ Coeficiente de variação (\%) = 11,99.

1 Coefficient of variation (\%) $=11.99$

Tabela 7 - Ganho médio diário (kg/dia) após o desmame dos cordeiros controle, com restrição alimentar pós-natal e com restrição alimentar pré-natal, abatidos em diferentes pesos

Table 7 - Weight gain ( $\mathrm{kg} /$ day) of control, postnatal and prenatal restricted lambs after weaning

\begin{tabular}{lccc}
\hline $\begin{array}{l}\text { Peso de abate } \\
\text { Slaughter weight }\end{array}$ & \multicolumn{3}{c}{$\begin{array}{c}\text { Tratamento } \\
\text { Treatment }\end{array}$} \\
\cline { 2 - 4 } & $\begin{array}{c}\text { Restrição pré-natal } \\
\text { Prenatal restriction }\end{array}$ & $\begin{array}{c}\text { Restrição pós-natal Controle } \\
\text { Postnatal restriction }\end{array}$ & Control \\
\hline & $0,273^{\mathrm{aA}}$ & $0,158^{\mathrm{cA}}$ & $0,228^{\mathrm{bA}}$ \\
35 & $0,248^{\mathrm{aA}}$ & $0,157^{\mathrm{cA}}$ & $0,217^{\mathrm{bA}}$ \\
25 & $0,212^{\mathrm{aB}}$ & $0,174^{\mathrm{aA}}$ & $0,180^{\mathrm{aA}}$ \\
15 & $0,014^{\mathrm{aC}}$ & $0,032^{\mathrm{aB}}$ & $0,030^{\mathrm{aB}}$ \\
Média geral $^{1}$ & $0,187^{\mathrm{a}}$ & $0,131^{\mathrm{c}}$ & $0,164^{\mathrm{b}}$
\end{tabular}

Overall mean

Médias seguidas da mesma letra minúscula na linha e maiúscula na coluna não diferem $(P<0,05)$ pelo teste Scott-Knott.

Means within a row followed by the same small letters and same capital letters do not differ $(P<0.05)$ by Scott-Knott test.

1 Coeficiente de variação $(\%)=18,54$.

1 Coefficient of variation $(\%)=18.54$

após o nascimento. Vários pesquisadores demonstraram que os efeitos da restrição pós-natal sobre o desempenho do animal podem ser minimizados pelo ganho compensatório, de acordo com o grau e o tempo que a restrição foi imposta (Kabbali et al., 1992; Murphy \& Loerch, 1994; Owens et al., 1993; Widdowson \& Lister, 1991).

Verificou-se que tanto a restrição pré-natal quanto a pós-natal afetaram o ganho de peso médio geral dos cordeiros (Tabela 7). No caso dos cordeiros com restrição alimentar pós-natal, o menor ganho de peso foi reflexo do menor consumo destes animais (Tabela 4). Os cordeiros sob restrição pré-natal, no entanto, tiveram consumo de ração semelhante ao do grupo controle, mas não apresentaram o mesmo desempenho, demonstrando que não superaram a restrição imposta durante a fase pré-natal, mesmo em uma fase mais tardia. Como discutido anteriormente, esse comportamento pode ser atribuído à alteração no peso à idade adulta desses animais, ocasionando maior deposição de gordura corporal e menor eficiência no ganho de peso que os animais do grupo controle.

À exceção dos animais de $15 \mathrm{~kg}$, os ganhos de peso médio dos cordeiros do grupo controle obtidos neste experimento foram superiores aos relatados por Motta (2000), Oliveira et al. (2003) e Arruda et al. (1981). O ganho de peso médio dos animais de $15 \mathrm{~kg}$ foi significativamente inferior ao dos demais tratamentos, provavelmente em razão do grande estresse causado pela desmama, que ocorreu muito próximo a este peso de abate.

$\mathrm{Na}$ Tabela 8 são apresentados os dados referentes ao consumo médio diário de matéria seca ( $\left.\mathrm{g} / \mathrm{kg} \mathrm{PV}^{0,75} / \mathrm{dia}\right)$, de energia metabolizável ( $\mathrm{kcal} / \mathrm{kg} \mathrm{PV} \mathrm{PV}^{0,75} / \mathrm{dia}$ ), de proteína bruta (g/kg PV $0,75 /$ dia) e de FDN (g/kg PV0,75/dia) após o desmame dos cordeiros.

Assim como ocorreu com o consumo médio diário, nesta fase do desenvolvimento do animal não houve efeito da restrição pré-natal sobre o consumo de MS, EM, PB ou FDN (g/kg PV $0,75 /$ dia).

Sibbald \& Davidson (1998), ao avaliarem os efeitos da nutrição pré-natal sobre o consumo voluntário após o desmame de cordeiros Scottish Blackface, também observaram que não houve diferença no consumo voluntário de cordeiros submetidos ou não à restrição pré-natal. De acordo com os autores, embora o peso e as dimensões do rúmen ao nascer indiquem menor desenvolvimento nos animais sob restrição pré-natal, estas diferenças desaparecem quando os animais são submetidos ao mesmo nível nutricional pós-natal. Portanto, os consumos semelhantes dos cordeiros sem restrição pós-natal neste trabalho se devem ao peso semelhante do rúmen (Tabela 9), uma vez que, segundo Fell \& Weekes (1975), citado por Sibbald \& Davidson (1998), em animais submetidos ao mesmo manejo nutricional, existe correlação positiva entre o peso do rúmen e o consumo voluntário.

Quanto ao efeito do peso sobre o consumo de MS, EM, $\mathrm{PB}$ ou FDN (g/kg PV ${ }^{0,75} /$ dia) dos cordeiros sem restrição pós-natal, excluindo os animais de $15 \mathrm{~kg}$, que apresentaram consumos significativamente inferiores ao dos cordeiros dos demais pesos, em razão do estresse provocado pela desmama, o consumo foi semelhante para animais com peso vivo de 25 a $45 \mathrm{~kg}$. Este comportamento no consumo de MS, EM, PB e FDN (g/kg PV $0,75 /$ dia) também foi observado por 
Tabela 8 - Consumo médio diário de matéria seca (g/kg PV0,75/dia), energia metabolizável (kcal/ kg PV0,75/dia), proteína bruta (g/kg PV0,75/dia) e FDN (g/kg PV0,75/dia) após o desmame de cordeiros dos grupos controle, restrição alimentar pré-natal e restrição pós-natal, abatidos com diferentes pesos

Table 8 - Average feed intake of dry matter (g/kg BW0.75/day), metabolizable energy ( $k c a l / k g B W 0.75 /$ day), crude protein

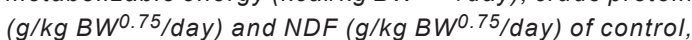
postnatal and prenatal restricted lambs after weaning

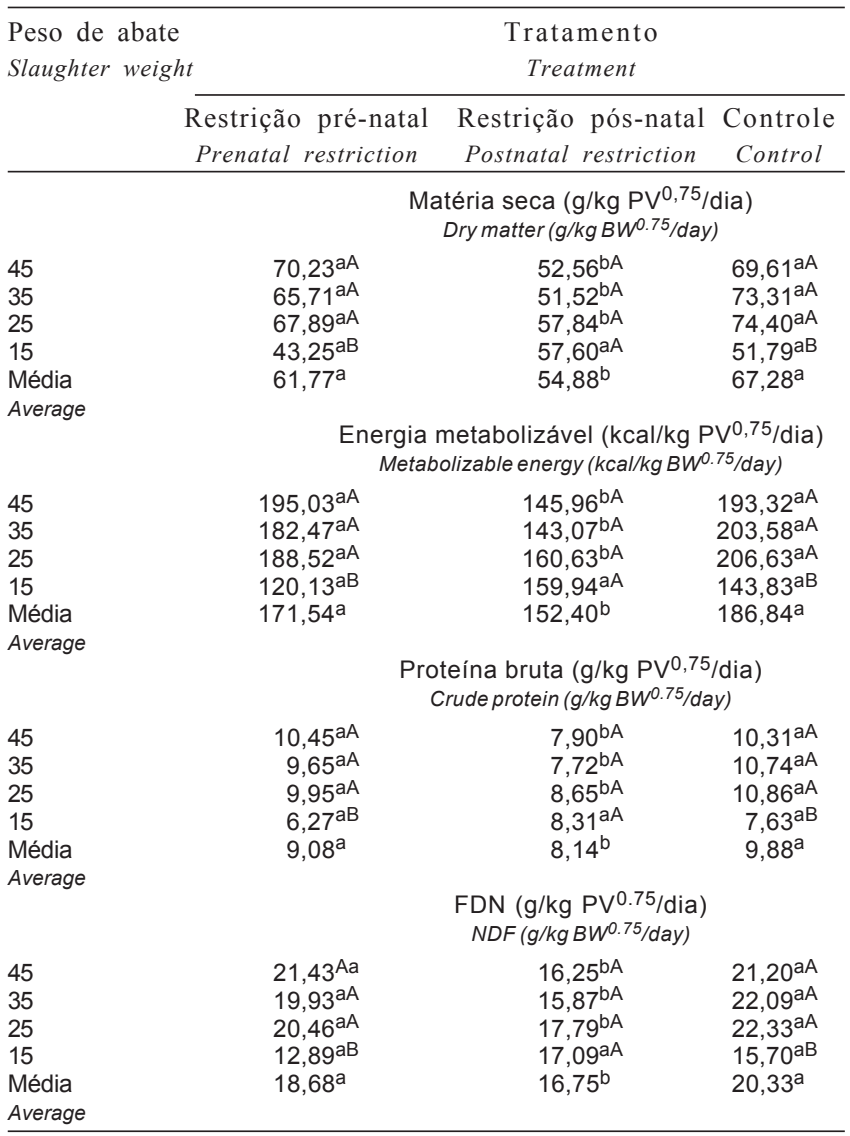

Médias seguidas da mesma letra minúscula na linha e maiúscula na coluna não diferem $(P<0,05)$ pelo teste Scott-Knott.

Means within a row followed by the same small letters and same capital letters do not differ $(P<0.05)$ by Scott-Knott test.

Furusho-Garcia et al. (2004), em cordeiros Texel x Santa Inês. Entretanto, esse autor não observou o mesmo comportamento em cordeiros Santa Inês puros, que apresentaram diminuição no consumo em função do aumento no peso vivo. Por outro lado, Santos (2002) constatou aumento no consumo de MS por unidade de tamanho metabólico com o incremento do peso de cordeiros Santa Inês.

De acordo com o ARC (1980), para dietas finas, como a utilizada neste experimento (dieta total contendo concentrado e feno moído), há uma correlação negativa entre o peso metabólico e a ingestão da dieta por unidade de peso metabólico. Entretanto, segundo esse conselho, os dados sobre consumo de matéria seca apresentam grande variação de acordo com os diferentes tipos de dietas utilizadas nos experimentos e, portanto, podem ocorrer diferenças na ingestão de matéria seca conforme o peso metabólico do animal.

Constam na Tabela 10 os resultados referentes à conversão alimentar dos cordeiros submetidos aos diferentes manejos alimentares e abatidos com diferentes pesos. Vale ressaltar que o peso do rúmen e a conversão alimentar foram as únicas variáveis que não apresentaram interação significativa, e, por isso, os resultados apresentados referem-se apenas à média geral dos tratamentos.

O manejo alimentar ao qual o animal foi submetido não afetou a conversão alimentar (Tabela 10), o que não era esperado, pois os cordeiros do grupo controle apresentaram ganho de peso significativamente maior que os demais animais e consumo semelhante ao dos cordeiros da restrição pré-natal. Segundo Lanna (1997), quanto maior a taxa de ganho maior a eficiência de conversão, em razão da diluição das exigências de mantença.

A não-significância da restrição sobre a conversão alimentar neste experimento se deve à grande variação ocorrida, principalmente nos animais de $15 \mathrm{~kg}$, que apresentaram, a maioria, perda de peso durante este período. A perda de peso ocasionada pelo estresse ao desmame, especialmente nos

Tabela 9 - Tamanho médio $(\mathrm{kg})$ do rúmen de cordeiros Santa Inês submetidos a diferentes manejos alimentares e abatidos em diversos pesos após o desmame

Table 9 - Average rumen size of Santa Ines lams fed different treatments after weaning

\begin{tabular}{|c|c|c|c|}
\hline \multirow{2}{*}{$\begin{array}{l}\text { Peso de abate } \\
\text { Slaughter weigh } \\
\mathrm{R}\end{array}$} & \multicolumn{3}{|c|}{ Tratamento } \\
\hline & $\begin{array}{l}\text { Restrição pré-natal } \\
\text { Prenatal restriction }\end{array}$ & $\begin{array}{l}\text { Restrição pós-natal } \\
\text { Postnatal restriction }\end{array}$ & $\begin{array}{c}\text { Controle } \\
\text { Control }\end{array}$ \\
\hline $\begin{array}{l}\text { Média geral }{ }^{1} \\
\text { Overall mean }^{2}\end{array}$ & $0,587^{\mathrm{a}}$ & $0,540^{\mathrm{b}}$ & $0,589^{\mathrm{a}}$ \\
\hline
\end{tabular}

Médias seguidas da mesma letra minúscula não diferem $(P<0,05)$ pelo teste Scott-Knott.

Means followed by the same small letters do not differ $(P<0.05)$ by Scott-Knott test.

${ }^{1}$ Coeficiente de variação $(\%)=8,46$.

1 Coefficient of variation $(\%)=8.46$.

Tabela 10 - Conversão alimentar dos cordeiros dos grupos sem restrição alimentar e com restrições pré e pós-natal abatidos com diferentes pesos

Table 10 - Feed:gain ratio of control, postnatal and prenatal restricted lambs after weaning

\begin{tabular}{lccc}
\hline $\begin{array}{l}\text { Peso de abate } \\
\text { Slaughter weight }\end{array}$ & \multicolumn{3}{c}{$\begin{array}{c}\text { Tratamento } \\
\text { Treatment }\end{array}$} \\
\cline { 2 - 4 } & $\begin{array}{c}\text { Restrição pré-natal } \\
\text { Prenatal restriction }\end{array}$ & $\begin{array}{c}\text { Restrição pós-natal } \\
\text { Postnatal restriction }\end{array}$ & $\begin{array}{c}\text { Controle } \\
\text { Control }\end{array}$ \\
\hline Média geral $^{1}$ & $4,96^{\mathrm{a}}$ & $4,58^{\mathrm{a}}$ & $4,81^{\mathrm{a}}$ \\
Overall mean & & & \\
\hline
\end{tabular}

Médias seguidas da mesma letra minúscula não diferem $(P<0,05)$ pelo teste Scott-Knott.

Means followed by the same small letters do not differ $(P<0.05)$ by Scott-Knott test.

${ }^{1}$ Coeficiente de variação $(\%)=42,96$.

${ }^{1}$ Coefficient of variation $(\%)=42.96$. 


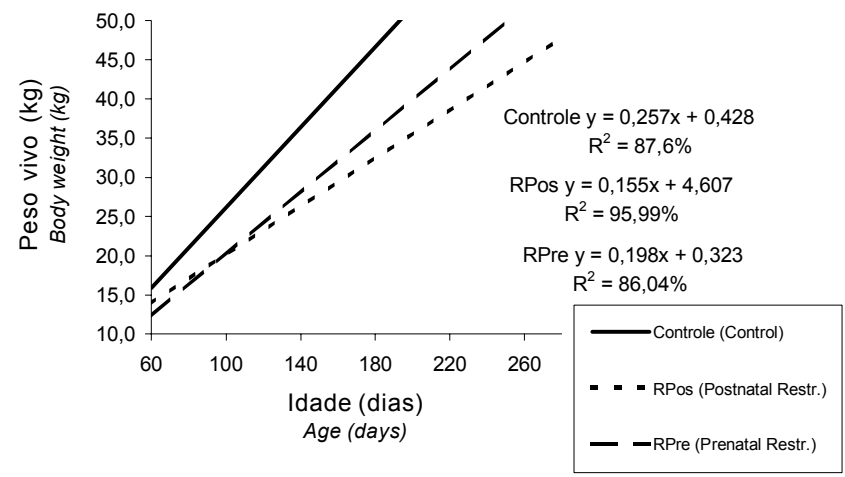

Figura 1 - Curvas de crescimento após o desmame dos cordeiros sem restrição alimentar (controle) e com restrições pré (RPre) e pós-natal (RPos).

Figure 1 - Growth curve of control, postnatal and prenatal restricted lambs after weaning.

cordeiros do grupo controle, resultou em índice de conversão alimentar extremamente alto nos animais de $15 \mathrm{~kg}$.

Os efeitos da restrição pós-natal sobre a eficiência de conversão alimentar foram observados por Murphy \& Loerch (1994), em cordeiros Hampshire x Targhee. Os autores concluíram que houve redução na conversão alimentar com a redução no nível de ingestão, pois a conversão alimentar dos cordeiros alimentados à vontade foi de 2,98 , enquanto a daqueles com alimentação restrita $(70 \%$ do consumo ad libitum) foi de 3,36.

Na Figura 1 são apresentadas as curvas de crescimento após o desmame dos cordeiros controle, com restrição pósnatal (RPos) e com restrição pré-natal (RPre).

Os coeficientes de determinação encontrados por meio equações de regressão indicam ajuste adequado dos dados, com pouca dispersão. Os coeficientes de regressão " $b$ " foram significativos $(\mathrm{P}<0,01)$ para todos os manejos alimentares, indicando aumento linear do peso do animal com o avançar da idade.

De acordo com as equações apresentadas, os coeficientes de regressão encontrados foram de 0,257; 0,198 e 0,155 para os cordeiros dos grupos controle, restrição pré-natal e restrição pós-natal, respectivamente. O ganho de peso determinado pela curva de crescimento foi maior que o ganho de peso médio (Tabela 7), como conseqüência do estresse da desmama dos cordeiros do grupo de $15 \mathrm{~kg}$, o que ocasionou a subestimação do ganho médio geral. Na curva de crescimento, este efeito foi minimizado, pois o ganho é função da relação entre o peso e a idade do animal, enquanto o ganho médio apresentado na Tabela 7 é uma média ponderal.
O ganho de peso dos cordeiros do grupo controle após o desmame $(0,257 \mathrm{~kg} / \mathrm{dia})$ foi semelhante ao observado por Vasconcelos et al. (2000), em cordeiros Santa Inês mantidos em confinamento dos 30 aos $45 \mathrm{~kg}$ de peso vivo $(0,252 \mathrm{~kg} /$ dia), e superior ao encontrado por Motta (2000), em cordeiros Texel $(0,189 \mathrm{~kg} / \mathrm{dia})$. Todavia, foi inferior ao verificado por Murphy \& Loerch (1994), em cordeiros Hampshire x Targhee $(0,387 \mathrm{~kg} / \mathrm{dia})$.

Foi realizada análise comparativa de equações lineares (Snedecor \& Cochran, 1967) entre as equações de crescimento dos animais submetidos aos diferentes manejos alimentares. As comparações foram feitas duas a duas e indicaram que o coeficiente de regressão foi superior para os cordeiros do grupo controle em relação aos das restrições pré $(\mathrm{P}=0,0801)$ e pós-natal $(\mathrm{P}<0,05)$.

O desempenho inferior dos cordeiros da restrição prénatal, em relação aos animais controle após o desmame, indica que estes animais não compensaram a restrição imposta, mesmo em uma fase mais tardia do desenvolvimento, resultando em maior idade de abate, consumo total de ração, maior ocupação da instalação e, conseqüentemente, maior custo ao produtor.

Entre os animais com alimentação restrita, a comparação dos coeficientes de regressão demonstrou que os cordeiros do grupo restrição pré-natal apresentaram ganho de peso superior aos da restrição pós-natal, o que também foi observado pela análise pontual das médias de ganho de peso (Tabela 7).

Ressalta-se que, embora os animais da restrição prénatal tenham apresentado desempenho superior aos da restrição pós-natal, os efeitos da restrição pré-natal ainda refletem no desempenho do animal mesmo quando submetido a um manejo nutricional correto após o nascimento, enquanto os efeitos da restrição pós-natal podem ser minimizados pelo ganho compensatório conforme o grau e o tempo que a restrição foi imposta.

\section{Conclusões}

A restrição pré-natal afetou o desempenho dos animais mesmo após o desmame, resultando em menor ganho de peso, em maior consumo total de ração e em maior idade de abate, indicando que estes animais não compensaram a restrição imposta durante a fase pré-natal, mesmo em uma fase mais tardia, o que justifica a importância da suplementação das ovelhas gestantes no terço final de gestação. 


\section{Literatura Citada}

AGRICULTURAL RESEARCH COUNCIL - ARC. The nutrient requirements of farm animals. London: 1980. $351 \mathrm{p}$.

ARRUDA, F.A.V.; OLIVEIRA, E.R.; BARROS, N.N. et al. Restolho da cultura de milho para ovinos da raça Santa Inês mantidos em confinamento. In: REUNIÃO ANUAL DA SOCIEDADE BRASILEIRA DE ZOOTECNIA, 18., 1981, Goiânia. Anais... Goiânia: Sociedade Brasileira de Zootecnia, 1981. p.323.

FURUSHO-GARCIA, I.R.; PEREZ, J.R.O.; BONAGURIO, S. Desempenho de cordeiros Santa Inês puros e cruzas Santa Inês com Texel, Ile de France e Bergamácia. Revista Brasileira de Zootecnia, v.33, n.6, p.1591-1603, 2004.

GREENWOOD, P.L.; HUNT, A.S.; HERMANSON, J.W. et al. Effects of birth weight and postnatal nutrition on neonatal sheep: I. Body growth and composition, and some aspects of energetic efficiency. Journal of Animal Science, v.76, p.2354-2367, 1998.

KABBALI, A.; JOHSON, W.L.; JOHNSON, D.W. et al. Compensatory growth on some body component weights on carcass and noncarcass composition of growing lambs. Journal of Animal Science, v.70, n.9, p.2852-2858, 1992.

KIRKPATRICK, D.E.; STEEN, W.J. Performance, carcass composition and energy retention of lambs offered two contrasting grass-based forages. Journal of Agricultural Science, v.132, n.2, p.117-126, 1999.

LANNA, D.P.D. Fatores condicionantes e predisponentes da puberdade e idade ao abate. In: SIMPÓSIO SOBRE PECUÁRIA DE CORTE: PRODUÇÃO DE NOVILHO DE CORTE, 4., 1997, Piracicaba. Anais... Piracicaba: Fundação de Estudos Agrários Luiz de Queiroz, 1997. p.41-78.

OLIVEIRA, M.V.M.; PEREZ, J.R.O.; FURUSHO-GARCIA, I.F. et al. Desempenho de cordeiros das raças Bergamácia e Santa Inês terminados em confinamento, recebendo dejetos de suínos como parte da dieta. Revista Brasileira de Zootecnia, v.32, n.6, p.1391-1396, 2003.

MOTTA, S. Ganho de peso, características da carcaça de cordeiros(as) em diferentes métodos de alimentação, pesos de abate e produção de leite de ovelhas. Santa Maria: Universidade Federal de Santa Maria, 2000. 93p. Dissertação (Mestrado em Zootecnia) - Universidade Federal de Santa Maria, 2000.
MURPHY, T.A; LOERCH, S.C. Effects of restricted feeding of growing steers on performance, carcass characteristics, and composition. Journal of Animal Science, v.72, p.2497-2509, 1994.

OWENS, F.N.; DUBESKI, P.; HANSON, C.F. Factors that alter the growth and development pf ruminants. Journal of Animal Science, v.71, n.11, p.3138-3150, 1993.

PIRES, C.C.; SILVA, L.F.; SCHLICK, F.E. et al. Cria e terminação de cordeiros confinados. Revista do Centro de Ciências Rurais, v.30, n.5, p.875-880, 2000.

SANTOS, C.L. Estudo do crescimento e da composição química dos cortes da carcaça de cordeiros Santa Inês e Bergamácia. Lavras: Universidade Federal de Lavras, 2002. 257 p. Tese (Doutorado em Zootecnia) - Universidade Federal de Lavras, 2002.

SIBBALD, A.M.; DAVIDSON, G.C. The effect of nutrition during early life on voluntary food intake by lambs between weaning and 2 years age. Animal Science, v.66, p.697-703, 1998.

SILVA, D.J.; QUEIROZ, A.C. Análise de alimentos (métodos químicos e biológicos). 3.ed. Viçosa, MG: Universidade Federal de Viçosa, 2002. 235p.

SNEDECOR, G.W.; COCHRAN, W.G. Statistical methods. 6.ed Iowa: Iowa State University Press, 1967. 593p.

VASCONCELOS, V.R.; LEITE, E.R.; BARROS, N.N. Terminação de caprinos e ovinos deslanados no Nordeste do Brasil. In: SIMPÓSIO INTERNACIONAL SOBRE CAPRINOS E OVINOS DE CORTE, 1., 2000, João Pessoa. Anais... João Pessoa: EMEPA, 2000. p.97-106

WIDDOWSON, E.M.; LISTER, D. Nutritional control of growth. In: PEARSON, A.M.; DUTSON, T.R. (Eds.) Growth regulation in farm animals. London: Elsevier, 1991. p.67-102.

WYNN, P.C.; THWAITES, C.J. The relative growth and development of the carcass tissues of merino and crossbred rams and wethers. Australian Journal Agricultural Research, v.32, p.947-956, 1981 . 